\title{
Geotechnical Hazards in Rocky Slopes (Northern Portugal): Focused on Methodology
}

\author{
José Filinto Trigo, Carlos Pacheco, João Fernandes, Pedro Ferraz, \\ Jorge Sousa, Rui Machado, Sara Duarte, Ana Mendes, Liliana Freitas, \\ José Teixeira, Luís Ramos, Maria José Afonso, and Helder I. Chaminé
}

\begin{abstract}
Interdisciplinary studies of rocky slopes stability have been performed on Northern Portugal, that allowed to establish a design methodology. This approach carries together the use of more traditional techniques, with the application of more recent technologies, such as unmanned aerial vehicles. This work presents a set of procedures that have been applied successfully in several case studies, describing the different stages, with an emphasis on the production of a ground threedimensional model. This model is generated from photographs obtained with successive drone flights, with overlapping. It is the support for the development of subsequent stages, especially for the characterisation of the trajectories of rockfalls and modelling, the development of susceptibility mapping and of rock slope hazard. In this context, the Natural Slope Quality Index (N-SQI), an adaptation of the Slope Quality Index (SQI), orientated to natural slopes, is presented. The Block Gravity Number (BGN), created in order to hierarchise rock blocks, selecting them for modelling, is also proposed.
\end{abstract}

J. F. Trigo $\cdot$ C. Pacheco $\cdot$ J. Fernandes $\cdot$ P. Ferraz $\cdot$ J. Sousa Division for Construction Studies (NEC), Department of Civil Engineering, School of Engineering (ISEP), P.Porto, Porto, Portugal

J. F. Trigo - R. Machado - S. Duarte - A. Mendes - L. Freitas · J. Teixeira · L. Ramos · M. J. Afonso $(\bowtie) \cdot$ H. I. Chaminé Laboratory of Cartography and Applied Geology (LABCARGA), Department of Geotechnical Engineering, School of Engineering (ISEP), P.Porto, Porto, Portugal

e-mail: mja@isep.ipp.pt

J. Teixeira

CEGOT and Department of Geography, Faculty of Arts,

University of Porto, Porto, Portugal

M. J. Afonso · H. I. Chaminé

Centre GeoBioTec|UA, Aveiro, Portugal

\section{Keywords}

Rockfalls - Slope geotechnics • Natural hazards •

Drones • Hydrological conditions

\section{Introduction}

Hazard describes any condition with the potential for causing an undesirable situation, that sometimes could incur in disasters (e.g. Wyllie and Mah 2004; Einstein and Sousa 2012). The triggering mechanism for failure involves both the presence of at least one factor (e.g. infiltration of water, earthquake, vegetation grow) and the existence or development of unfavourable conditions for stability, such as blocked drainage paths and high slope angle (Pantelidis 2009).

In Northern Portugal, rock slope instability is a common process associated with rockfalls. These mass movements occur mainly in areas where the geological, hydrological and geomorphological conditions promote the natural landscapes with the presence of high slopes and rocky boulders with different shapes and dimensions. Sometimes, these rockfalls involve significant damage and are often associated with natural phenomena, such as high-intensity and/or long-term precipitation (Wyllie and Mah 2004; Volkwein et al. 2011). Also, they may result from anthropic actions, such as the destruction by wildfires of the vegetation cover. The change in the water conditions (namely water content or pressure) is generally the major factor responsible for triggering this kind of slope instability. Water is also an important weathering factor that can play a significant role with respect to rock discontinuities and thus rock mass behaviour. The increase of precipitation (frequency and intensity) highlights new problems concerning rock mass stability (Sandersen et al. 1996).

Northern Portugal is classified, in climate terms, as Atlantic type, being temperate with a hot and dry summer. It is very influenced by the orientation of the relief, which 
represents the first obstacle to the air masses from the West, after a long journey over the Atlantic Ocean. In this region, precipitation decreases from the coastal areas to inland, due to orographic barriers, and may vary by altitude control from maximum values around $3000 \mathrm{~mm} /$ year in the NW mountains (Gerês and Cabreira) to less than $500 \mathrm{~mm} /$ year in the inner Douro Valley. The NW façades have average values around $1200-1500 \mathrm{~mm} /$ year, and most of the precipitation is concentrated in the rain season, from October to March. This intense precipitation is the cause for the presence of water in the rocky masses and has often a double negative effect on their stability.

In fact, the percolation of water into the discontinuities induces a pressure increase on the adjacent rock surfaces and promotes the decrease of the shear strength of these surfaces. Water is also responsible for the transport of small particles that accumulate in the discontinuities, filling them with material usually poorly resistant and very deformable. Instead, in filled discontinuities, water can wash these particles.

On the isolated blocks that occur, frequently, on the slopes of Northern Portugal, water is also an important factor for the decreasing of their stability. The water that flows on the base of the blocks erodes the material, usually of residual soil origin, that constitutes its support surface, promoting a loss of support from underneath. This water flow is also responsible for the transport of residual soil material and smaller rock blocks from higher elevations, which may constitute an additional instability action on the bigger blocks. This effect of temporary water flow generated after an intense or continuous precipitation that usually flows under a torrential regime is more evident when the blocks are located close to a line of thalweg. This way, the process of blocks transportation and their fall along the slope can be triggered more easily. Finally, it is interesting to note that many rockfalls happen on summer time, corresponding to periods of time without precipitation, but with high thermal amplitudes.

\section{Methodology Applied to the Study of Natural Rocky Slopes Stability in Northern Portugal}

Interdisciplinary studies of rock slopes stability have been performed on Northern Portugal (e.g. S. Simão site, Amarante; S. Cristovão and Mourilhe sites, Cinfães; Santo Ovídio site, Gaia; Joane site, Famalicão) that allowed to establish a sustainable design methodology. That constraint allows always to design with nature and even design with hazards and/or rock engineering risks (e.g. Einstein and Sousa 2012; Hudson and Feng 2015). The approach requests an integrated and balanced understanding of climatology, applied geomorphology, hydrology, engineering geology, geotechnics and engineering methods. This integrative approach carries together the use of more traditional techniques, supported by a detailed mapping and fieldwork, with the application of more recent technologies, such as unmanned aerial vehicles (UAV), usually known as drones.

This methodology involved (Fig. 1), on a first stage, a topographical, hydroclimatological, morphotectonic and geostructural surveys and characterisation of the study area and, in a subsequent stage, a geotechnical, geomechanical and hydrological/hydrogeological assessment. The main geological, hydrogeological, geotechnical and geomechanical constraints were compiled and integrated along the rocky slopes. A high-precision GPS (Trimble GeoExplorer) was used for the fieldwork surveys. In addition, the use of Geographic Information Systems (GIS) on rock slope stability, using basic analysis tools for spatial management and data manipulation, has become more common.

The study of rock mass outcrops includes the description, evaluation and modelling of the mechanical properties of the intact rock and the rock anisotropies. The scanline sampling technique of discontinuities has been applied to the rocky mass faces for the rock mass description. This method includes placing a tape along the length of an outcrop and determining its orientation. All the basic geologic and geotechnical rock mass parameters are recorded and surveyed. To establish the main discontinuity sets, the structural geology data collected at the slope sites were analysed with Dips software package (Rocscience). Weathering grade $(W)$, fracture intercept $(F)$ and seepage conditions of rock material were used. Furthermore, uniaxial compressive strength (UCS) was estimated by Schmidt Rebound Hardness and Point Load Test (PLT). In order to classify the quality of the rocky masses, the following geomechanical classification systems and/or geotechnical indexes are the key: rock mass rating (RMR), slope mass rating (SMR) and geological strength index (GSI). SMR classification was also essential to evaluate the stability of the slopes and to offer insights into the main potential local slope failure mechanisms. In addition, other slope-based classifications systems could be applied to correct understanding of the hydrogeomechanical quality such as $Q$-slope, HP-Value and also the important inputs from Hack (2002), Pantelidis (2009), Bauer and Neumann (2011) and Pinheiro et al. (2015).

Simultaneously, a detailed visual inspection of the studied rock slopes is carried out, identifying the potential unstable blocks. This characterisation aims to establish a hierarchisation of the blocks, to be able to select the most unstable and to model their fall along the slope, using an automatic calculation program.

Therefore, a Block Gravity Number (BGN) was defined, which is a function of: (a) the weight and shape of the block, (b) the slope geometry, namely the slope angle, (c) the type 
Fig. 1 General and conceptual flow chart of the on-site investigation methodology to assess geotechnical hazards in natural rock slope failures

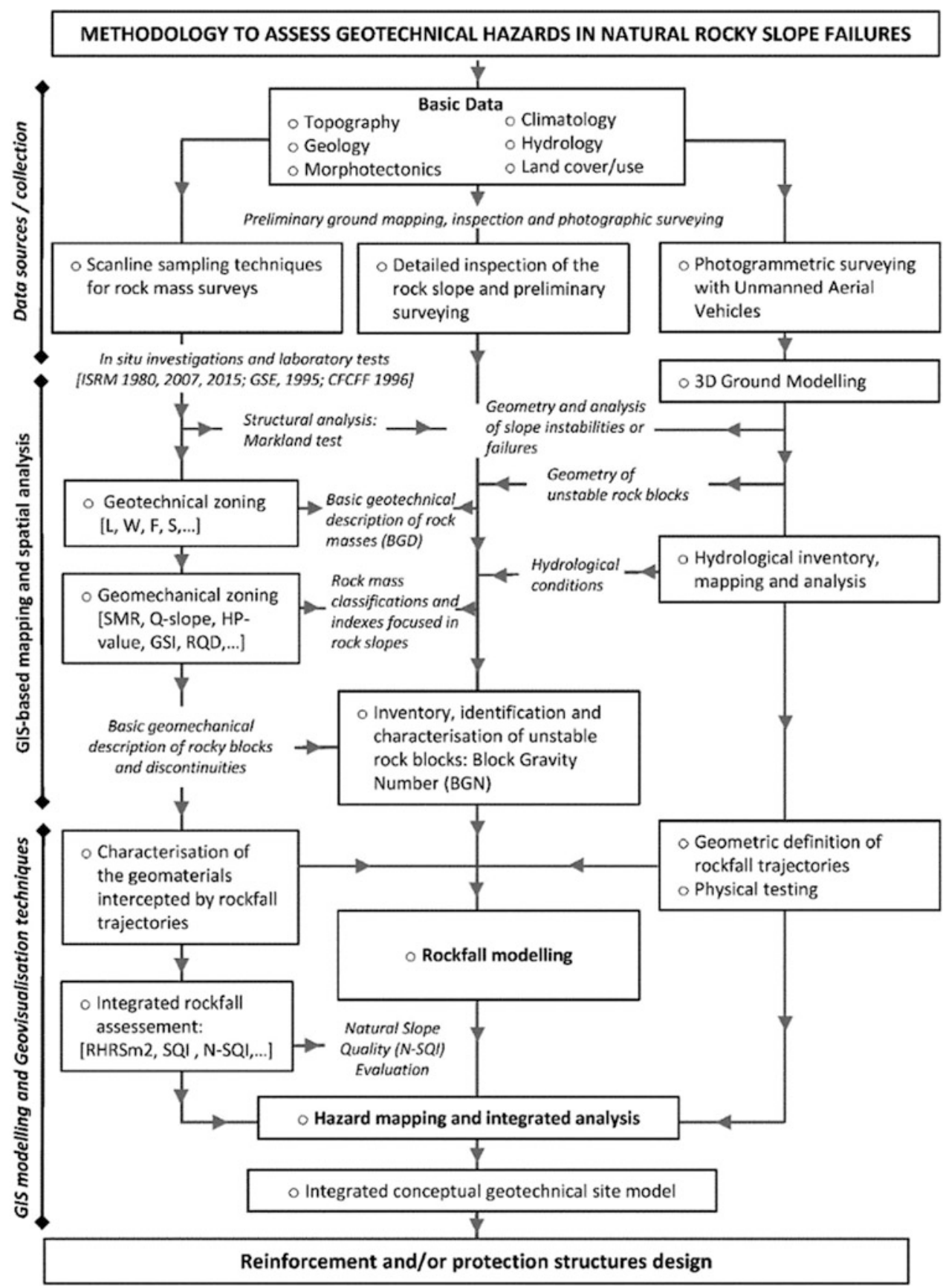

of material that exists on its potential fall trajectory and (d) a set of factors characteristic of the block, identified as anomalies. These anomalies are related with: (a) discontinuities and their aperture, (b) the evidence of loss of support from underneath, (c) the presence of vegetation with an instability effect, (d) indicators of block displacement, (e) the existence of soil- or rock-like material acting on the surface of the block, with an instability effect and (f) the presence of water in the discontinuities or in the base of the blocks. Each of these factors has associated a score and the sum is the classification of the BGN, which permits the hierarchisation of the blocks.

To evaluate the rockfall hazard of the slopes, the Slope Quality Index (SQI) proposed by Pinheiro et al. (2015) was applied with some adaptation to rock hillslopes (e.g. $\mathrm{S}$. Simão site, Amarante). This index is a practical system developed to obtain a quality index for rock slopes in highway infrastructures. The implementation of this index in 

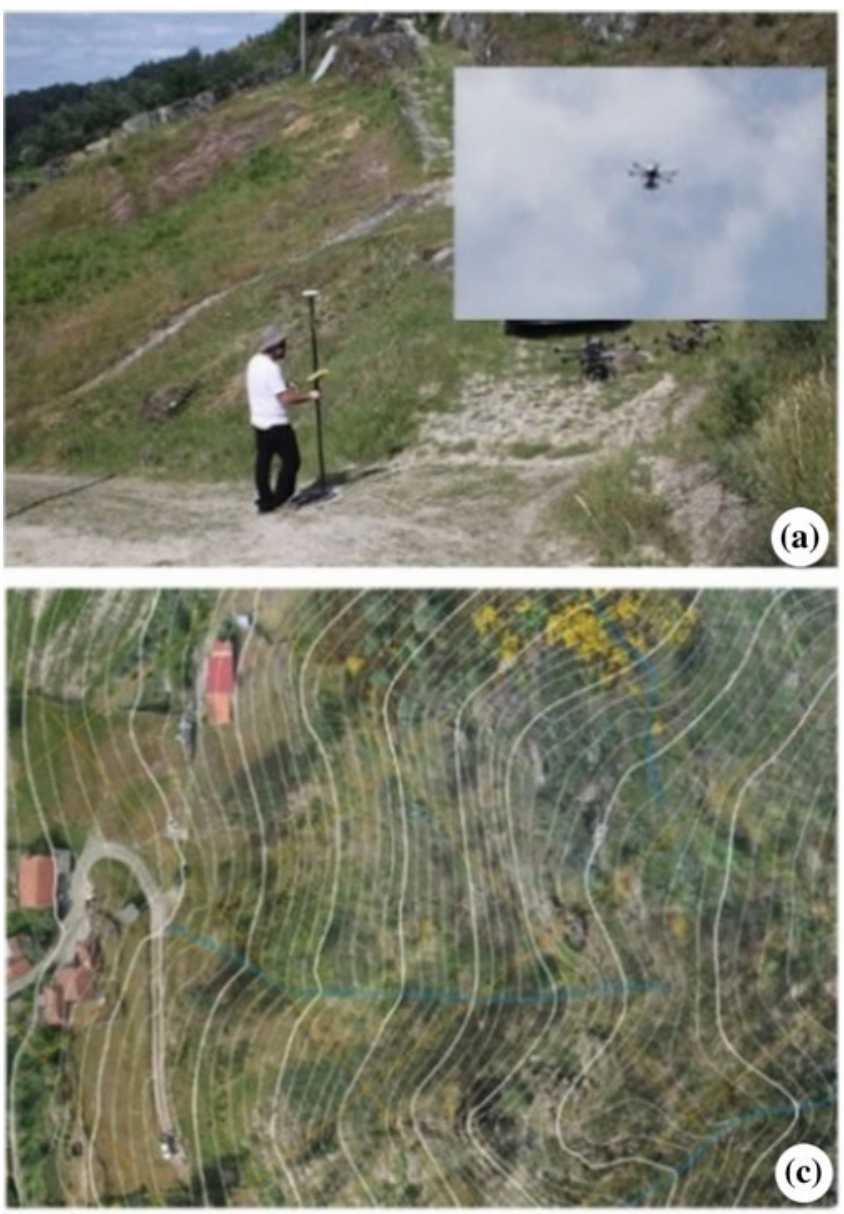

Fig. 2 Some aspects of the methodological approach: a high-precision GPS and UAV techniques to topographical and photogrammetric surveys; b geotechnical scanline sampling surveys; c orthophotomap

natural landscape scenarios led its adaptation and the proposal of the Natural Slope Quality Index (N-SQI), namely, introducing, in the original SQI, an additional parameter in the 'environmental/traffic factor', related to the presence of buildings on the bottom of the slope. The combination of the susceptibility analysis, given by the multiparameter rating systems-RMR, SMR and GSI - with N-SQI, leads to the final step of hazard assessment, the rockfall susceptibility and hazard mapping/zoning.

The use of UAV permits a high-resolution photographic survey of the slope. Photographs are obtained with an interval of $2 \mathrm{~s}$ and with an overlap of more than $60 \%$. Flights are carried out at different altitudes and, whenever possible, photographs are taken vertical to the slope. This way, it can be obtained a resolution of $1 \mathrm{~cm} /$ pixel. The data collected with the UAV are processed with photogrammetry OpenDroneMap software that permits to generate a high-resolution georeferenced orthophotomaps, as well as a three-dimensional model of the slope. The digital elevation model permits to calculate several parameters of the slope
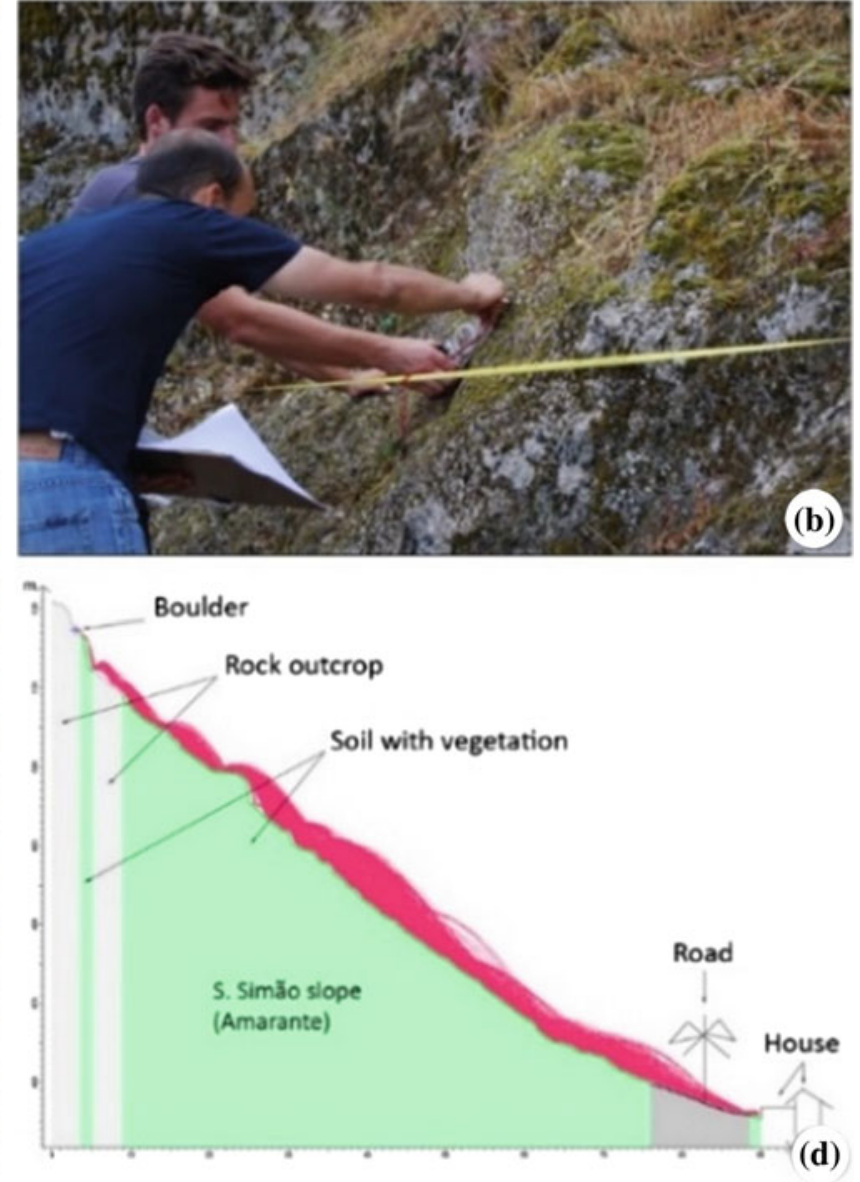

with contour lines, derived from UAV survey; d rockfall modelling (analysis with RocFall software by Rocscience Inc.-https://www. rocscience.com)

(e.g. length, gradient, height, etc.) and of the rock blocks (e.g. volume and shape). In addition, this model allows the definition of cross sections, which help to understand, in a more detailed way, the slope morphology. Also, it supports the design and performance evaluation of rockfall protection systems (Fig. 2).

\section{Concluding Remarks}

Rockfall susceptible areas can be assessed and predicted throughout integrative and multidisciplinary approaches, and thus, rockfall damage can be decreased through prevention efforts. The presented methodology was successfully applied to several case studies in Northern Portugal. This methodology puts together traditional approaches with innovative technologies, with detailed analyses both at the rocky block scale and at the slope scale. The proposal of the Block Gravity Number (BGN) is very useful on the optimisation of the rocky blocks selection to consider on the rockfall 
modelling. Additionally, the N-SQI index helps to the validation of the rockfall susceptibility and hazard mapping and zoning.

Acknowledgements This study was carried out under the framework of the LABCARGA|ISEP re-equipment program (IPP-ISEP|PAD'2007/08). The authors would like to thank the reviewers for helpful comments and inputs.

\section{References}

Bauer M, Neumann P (2011) A guide to processing rock-fall hazard from field data. In: Vogt N, Schuppener B, Straub D, Bräu G (eds) Proceedings of the 3rd international symposium on geotechnical safety and risk, ISGSR 2011. Munich, Germany, Bundesanstalt für Wasserbau, Karlsruhe, pp 149-156

Einstein HH, Sousa LR (2012) Risk in slopes. In Sousa LR, Vargas E, Jr, Fernandes MM, Azevedo R (eds) Innovative numerical modelling in geomechanics. CRC Press, pp 201-210
Hack R (2002) An evaluation of slope stability classification. In: Dinis da Gama C, Sousa LR (eds) Eurock'2002, ISRM, Funchal, Sociedade Portuguesa de Geotecnia, pp 3-32

Hudson JA, Feng X-T (2015) Rock engineering risk. ISRM book series. CRC Press, London

Pantelidis L (2009) Rock slope stability assessment through rock mass classification systems. Int J Rock Mech Min Sci 46:315-325

Pinheiro M, Sanches S, Miranda T, Neves A, Tinoco J, Ferreira A, Correia AG (2015) A new empirical system for rock slope stability analysis in exploitation stage. Int J Rock Mech Min Sci 76:182-191

Sandersen F, Bakkehoi S, Hestnes E, Lied K (1996) The influence of meteorological factors on the initiation of debris flows, rockfalls, rockslides and rockmass stability. In: Proceedings of the 7th international symposium on landslides, vol 1, pp 97-114

Volkwein A, Schellenberg K, Labiouse V, Agliardi F, Berger F, Bourrier F, Dorren LKA, Gerber W, Jaboyedoff M (2011) Rockfall characterisation and structural protection: a review. Nat Haz Earth Syst Sci 11:2617-2651

Wyllie DC, Mah CW (2004) Rock slope engineering: civil and mining, 4th edn. Spon Press, London 